\title{
Structural characterization of inkjet printed capacitor layers in various technological conditions
}

\author{
Milena Kiliszkiewicz, Dariusz Przybylski and Fan Felba \\ Department of Microsystems, Faculty of Microsystem Electronics and Photonics, \\ Wroclaw University of Science and Technology, Wroclaw, Poland, and \\ Ryszard Korbutowicz \\ Department of Microelectronics and Nanotechnology, Faculty of Microsystem Electronics and Photonics, \\ Wroclaw University of Science and Technology, Wroclaw, Poland
}

\begin{abstract}
Purpose - The purpose of this paper is to analyze the individual steps during the printing of capacitor structures. The method of substrate preparation, the obtained roughness of conductive and dielectric layers are examined. Moreover, the capacitances of the obtained capacitors were examined.

Design/methodology/approach - Surface roughness and microscopic analysis were used to assess the quality of printed conductive structures. Two criteria were used to assess the quality of printed dielectric structures: the necessary lack of discontinuity of layers and minimal roughness. To determine the importance of printing parameters, a draft experimental method was proposed.

Findings - The optimal way to clean the substrate has been determined. The most important parameters for the dielectric layer (i.e. drop-space, table temperature, curing time and temperature) were found.

Research limitations/implications - If dielectric layers are printed correctly, most problems with printing complex electronic structures (transistors, capacitors) will be eliminated.

Practical implications - The tests performed identified the most important factors for dielectric layers. Using them, capacitors of repeatable capacity were printed.

Originality/value - In the literature on this subject, no factors were found which were responsible for obtaining homogeneous dielectric layers.
\end{abstract}

Keywords Design of experiment, Inkjet printing, Conductive layers, Dielectric layers, Flexible electronics, Printed capacitor

Paper type Research paper

\section{Introduction}

The number of publications devoted to this subject indicates that recently, the interest in organic and polymer electronic devices has been growing. Various printing techniques such as screen or inkjet printing are increasingly used to manufacture such devices (Liu et al., 2003). Inkjet printing is an additive, digital, non-contact and non-mask method in which very small, free-falling droplets of ink from nozzle are generated and create the desired forms on a substrate (Brodeala et al., 2012; Felba, 2018). Substrates can be both flexible (usually polymers) and rigid (e.g. glass, ceramic), but the composition of inks define the properties of printed forms. If the ink contains electrically conductive particles, some conductive elements of electronic devices are created such as simple electrodes or more complicated structures; UHF antennas (Sowade et al., 2015); microstrip line (Szostak et al., 2019); or ring resonator (Jasińska et al., 2019). Alternate printing of layers with different properties (electrically conductive, semiconductive or

The current issue and full text archive of this journal is available on Emerald Insight at: https://www.emerald.com/insight/0954-0911.htm

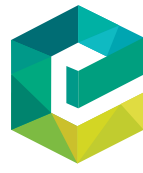

Soldering \& Surface Mount Technology $32 / 4$ (2020) 235-240

Emerald Publishing Limited [ISSN 0954-0911] [DOI 10.1108/SSMT-11-2019-0039] dielectric) enables production of complete electronic structures. In this way capacitors (Brodeala et al., 2012), thin-film transistors (Sowade et al., 2016), organic thin-film transistors, polymer light emitted diodes (Liu et al., 2003) or organic light-emitting diodes (De Gans et al., 2004) can be produced.

One of the most important criteria for printed electronics is the accuracy and uniformity of the printed layer (Perelaer et al., 2010). Well-defined morphology has a positive effect on electrical parameters and the potential application of technology in commercial use, especially of multilayer structures. However,

(C) Milena Kiliszkiewicz, Dariusz Przybylski, Jan Felba and Ryszard Korbutowicz. Published by Emerald Publishing Limited. This article is published under the Creative Commons Attribution (CC BY 4.0) licence. Anyone may reproduce, distribute, translate and create derivative works of this article (for both commercial and non-commercial purposes), subject to full attribution to the original publication and authors. The full terms of this licence may be seen at http://creativecommons.org/licences/by/4.0/legalcode

This research was supported by the Statutory Grant of, Faculty of Microsystem Electronics and Photonics, Wroclaw University of Science and Technology, Department of Microsystems. The authors wish to thank Piotr Pokryszka for help with measuring of the contact angle.

Received 22 November 2019

Revised 8 April 2020

28 April 2020

Accepted 5 May 2020 
the parameters and repeatability of the printed layers depend on many material and technological factors. The most important seems to be material and method of substrate preparation, viscosity and surface tension of the ink and printing parameters. The assessment of inkjet printing repeatability by minimizing the influence of uncontrolled factors was carried out by printing of capacitor structures, as capacitor functionality largely depends on the homogeneity of the dielectric layers.

It is known that the method of preparing the substrate surface affects the value of the wettability (contact) angle (Yuan and Lee, 2013) (Figure 1). Relatively small contact angles $\left(\theta<90^{\circ}\right)$ are characteristic to high wettability of substrates, while if the contact angles are large $\left(\theta>90^{\circ}\right)$, it is characteristic to low wettability. In fact, hydrophobic surfaces (with low wettability) allow better control of the process enabling printing of more sophisticated structures, but the adhesion of inkjetted materials to the surface is better in the case of better wettability (Miettinen et al., 2008).

\section{Materials and methods}

\subsection{Printer}

For printing, the Dimatix DMP 2831 inkjet printer, manufactured by FUJI FILM, was used. The volume of the droplet, crated in the drop-on-demand principle (ejects when the pulse of voltage is applied) (Le, 1998) is $10 \mathrm{pl}$. The printing head has 16 squares of 21.5 microns nozzles which are located in distance of 254 microns from each other.

The Dimatix 2831 printer resolution can support up to 5,080 DPI. Different resolutions were used during printing, which is implied by changing the angle of the print head. This makes it possible to change the print resolution, i.e. the distance between ink droplets on the substrate. The substrate is mounted to a temperature-controlled table called in this work as printer hotplate.

\subsection{Substrate}

The Melinex OD film from Du Pont (125 $\mu \mathrm{m}$ thick) was used as the substrate. This film was cleaned in three various ways:

1 washing using only deionized water in an ultrasonic cleaner Branson 8210 for 10 min;

2 washing with deionized water in the ultrasonic cleaner for $10 \mathrm{~min}$, pulling out and waiting to dry (about $20 \mathrm{~min}$ in room temperature) and washing with isopropanol in ultrasonic cleaner; and

3 washing with deionized water in the ultrasonic cleaner for $10 \mathrm{~min}$, pulling out and waiting to dry (about $20 \mathrm{~min}$ in room temperature) and washing with isopropanol in the ultrasonic cleaner, pulling out and waiting to dry (about $20 \mathrm{~min}$ in room temperature) and washing in acetone for $10 \mathrm{~min}$.

\subsection{Conductive layers}

Conductive layers were printed using Ag nanoparticle ink (AX JP-60n) from Amepox Microelectronics Ltd. The ink with the viscosity of $\sim 6 \mathrm{mPa} \cdot \mathrm{s}$ contains about $20 \%$ silver particles with dimensions of several dozen nanometers (Amepox, 2020). To

\section{Figure 1 Contact angle}

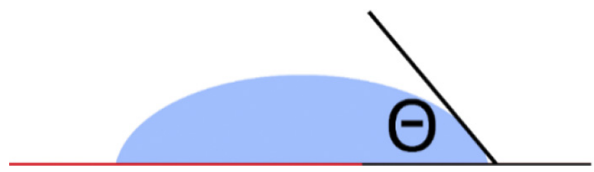

choose the best printing parameters, the rectangle about length $3 \mathrm{~mm}$ and form of different width $(100,300,500$ and 1,000 $\mu \mathrm{m})$ were printed with resolution of 1,693.33 [dpi], which corresponds to $15 \mu \mathrm{m}$ drop space. One nozzle and hotplate temperature of $40^{\circ} \mathrm{C}$ were used for printing. The samples were sintered at $150^{\circ} \mathrm{C}$ for $1 \mathrm{~h}$ in the Binder $\mathrm{GmbH}$ convection oven. Then the printing structures were observed using Zeiss AxioVision optical microscopy. The print correctness criterion was the best compatibility of the dimensions of printed forms with the assumed printing parameters and homogeneity of the printed layer. This allowed the selection of the best printing parameters and substrate preparation.

\subsection{Dielectric layers}

The dielectric layer is one of the basic factors for the obtained capacities of the electronic element. For creating this layer, several different dielectric inks can be used in inkjet printing technology, for example, polytetrafluoroethylene, poly(methyl methacrylate) and poly(4-vinylphenol) (PVP) (Brodeala et al., 2012) or crosslinked poly-4-vinylphenol (cPVC) which was used in this research. The ink was made by the authors with poly(4-vinylphenol) (PVP), poly(melamine-co-formaldehyde) methylated and propylene glycol monomethyl ether acetate. The samples for testing were printed in the form of squares $(5 \times 5 \mathrm{~mm})$ and then dried in Binder $\mathrm{GmbH}$ convection oven. Similar to conductive layers, for testing the Melinex OD film from Du Pont $(125 \mu \mathrm{m}$ thick) was used as the substrate.

For finding the importance of printing parameters the Taguchi method of experiment design (DoE) was proposed. This method is based on statistical analysis in which the orthogonal arrays are used (Ross, 1988). In the first steep of the experiment, the four factors with two levels were proposed, which needs L8 type the orthogonal array.

\subsection{Contact angle and surface parameters}

The contact angle (Figure 1) was measured using a goniometer (PG-X Fobro System AB) with deionized water as a liquid.

The profile, as well as the roughness of conductive layers, was measured for edge printed structure. The measuring process has been performed on Precision Measurement System Form Talysurf 120 made by Taylor Hobson Precision. The measuring probe with a sphere with $2 \mu \mathrm{m}$ diameter was used. The profiles of the sample were measured in the center and with a length of $2 \mathrm{~mm}$. The sample with a width of $1,000 \mu \mathrm{m}$ was used to measure the surface profile. The analysis of the profiles of the samples surface profiles was performed using Talysurf software.

The surfaces of printed dielectric layers were analyzed with the use of optical profilometer Talysurf CCI Lite made by Taylor Hobson. The samples have been illuminated by a halogen light source with the objective glass with $\times 10$ magnification. The interference bands from the samples have been found. For the interferometric analysis, the $Z$-axis travel has been set in the range of the occurrence of the interference bands. The optical profilometer software scanned the surface of the.

The analysis of the measured results of scanning of the surface of samples has been performed on TalyMap Gold 5.0 software. At the beginning of analyzing, the surface was leveled. Then, the roughness parameters from ISO 25178 group were calculated. The analyzed region of the samples was set as the center of the sample with size $2 \times 2 \mathrm{~mm}$. Therefore, the 
analyzing process was recurrent for all samples. For assessing the quality of printed structures, two criteria were applied; necessary lack of layer discontinuity and minimum roughness was tested using an optical profilometer.

\subsection{Capacitors structure}

Selected printing parameters of individual layers enabled inkjet printing of the capacitor structure on the elastic substrate (Melinex OD). In the first step, the Melinex OD was cleaned with using cleaning way (b) which results from the analysis of the research presented below. Next, the capacitor covers was printed with $\mathrm{Ag}$ nanoparticle ink. Based on previous experience with printing conductive structures, it has been proposed print resolution of $15 \mu \mathrm{m}$ and temperature of printer hotplate of $40^{\circ} \mathrm{C}$.

The size of the structure was $9 \times 9 \mathrm{~mm}$. The covers were sintering at temperature of $150^{\circ} \mathrm{C}$ for $1 \mathrm{~h}$ in the Binder $\mathrm{GmbH}$ over. In next step, the dielectric layers with using the best printing parameters (obtained through DoE analysis) in the pattern of square $15 \times 15 \mathrm{~mm}$ were printed on the capacitor covers.

A few dielectric layers were printed one on top of the other; each layer was dried at $130^{\circ} \mathrm{C}$ for $30 \mathrm{~min}$ in convection oven. Next, the covers of size of $9 \times 9 \mathrm{~mm}$ were printed with Ag nanoparticle ink. Finally, the samples were sintered at temperature of $150^{\circ} \mathrm{C}$ for $1 \mathrm{~h}$.

For the measure of the capacitor structure, a precision multimeter Fluke 8846A was used. Because the printed structure was delicate and using typical probes may destroy the surface of the capacitor cover, the special probes with rounded tip and spring in the middle were used.

\section{Results}

\subsection{Contact angle}

The results of influence the substrate washing method on the contact angle value are shown in Figure 2. To obtain the results, five measurements were taken for each cleaning method. Then, both, the mean vale and standard deviation was calculated. It can be seen that the smallest contact angle was obtained using the (c) way of surface cleaning; however, all measured angles have values below $90^{\circ}$, which indicates that after each method of surface preparation, it is rather hydrophilic (in relation to the fluid used in tests). Considering this, further tests are needed with the use of fluids forming subsequent capacitor layers.

Figure 2 Contact angle of the substrates Melinex OD surface after various cleaning methods

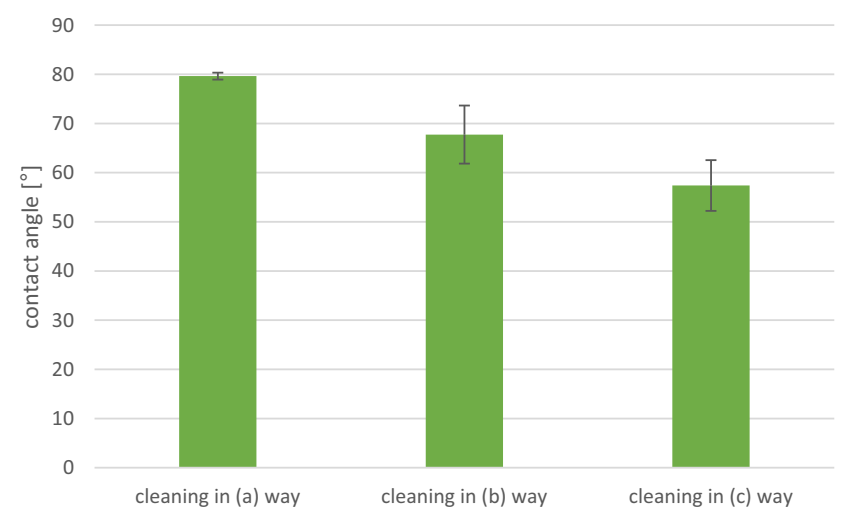

\subsection{Conductive layers}

The surfaces of the printed and sintered conductive layers were observed using Zeiss Axio Imager M2m microscope with the magnification of $\times 5$. Analysis of the structure showed some defects when the foils were cleaning in (a) and (c) ways.

In Figure 3(a), it can be seen that the most discontinuous layer (there are cracks, loss of materials) was obtained for cleaning method (a). This is probably owing to the fact that the surface of the substrate was still dirty and the ink had not covered the substrate evenly. This cleaning method [(a) way] is therefore inefficient. Cleaning with deionized water and isopropanol [(b) way] has cleaned the surfaces from dirt thus making the printed layer uniform [Figure 3(b)]. There are no material losses in the printed structure. Cleaning with deionized water, isopropanol and acetone [(c) way] has worsened the printout [Figure 3(c)]. It is likely that acetone may have damaged the substrate surface. As a result, given the "most homogeneous layer" criterion, the way (b) cleaning the substrate was established as the best.

The second criterion is also important - repeatability and compliance of the printed layer dimensions with the designed model. To evaluate this condition, stripes of different width were printed. According to the model, this width was 100, 300, 500 and $1,000 \mu \mathrm{m}$. After printing and sintering, each sample was measured at five random locations and dimensions were compared to the model. The results as the deviation of printed structures size vs cleaning way are shown in Figure 4. It can be seen that in any case the smallest deviations occur with cleaning in (a) way. This confirms the observation (Miettinen et al., 2008) that a larger contact angle (Figure 2) allows better control the dimensions of printed structures. The deviations of size in case of cleaning in (b) and (c) ways are similar and higher than in the case (a). However, what is obvious, the relative dimensional inaccuracy decreases as the size of the structure increases. So, with larger structure sizes, there may be a more important criterion "most homogeneous" layer and one should choose (b) cleaning way.

For a different kind of substrate cleaning, the roughness of printed and sintered layers was measured. The results are shown in Figure 5. It can be seen that for (a) cleaning way [Figure 5(a)] the structure is very uneven and for (b) and (c) methods [Figure 5(b) and $5(\mathrm{c})$ ] - more uniform. However, this assessment is very subjective; therefore, a thorough analysis of the surfaces was made.

For the comprehensive analysis of the surface structure, according to ISO 4287, different roughness indicators were taken into account. The results were obtained by measuring five times the same sample at different locations. In the analysis, the "coffee-ring" effect was omitted because it was considered to introduce too big errors into the results, and the authors wanted to analyze the surface of the printed structure, not the edges. The results are presented in Figure 6, wherein the criterion should be the most even surface.

Figure 3 Printed conductive structures on substrates with different cleaning ways

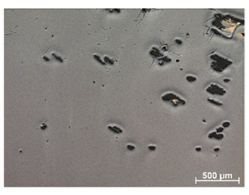

(a)

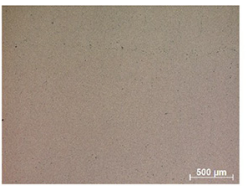

(b)

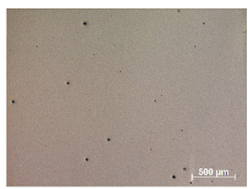

(c) 
Figure 4 Absolute value of the difference of printed lines relative to the pattern dimensions of the $\mathrm{Ag}$ ink deposition on the Melinex OD substrates

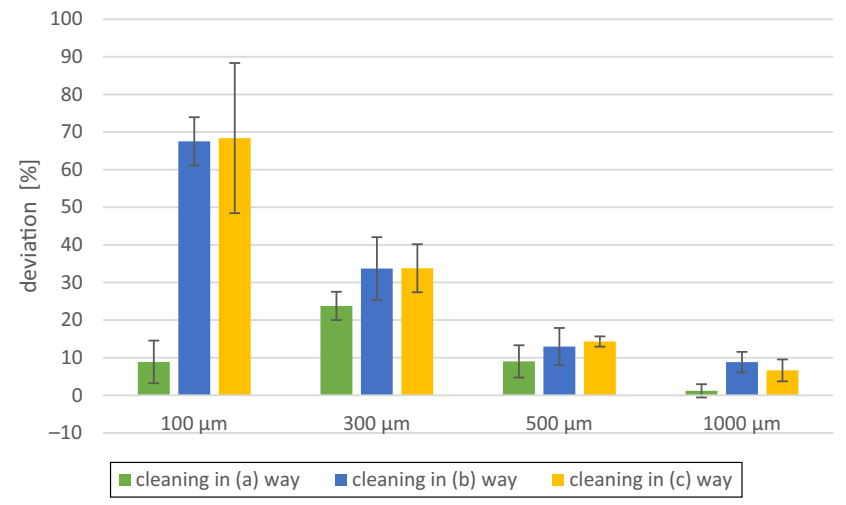

Analyzing the surface roughness according to various indicators, it is not possible to conclude which of the applied methods of cleaning the substrate $(a, b$ or $c)$ is the best. However, some regularity can be observed if the standard deviation is analyzed; for almost all indicators, this value is the smallest for the method (b). This means that the repeatability of the printed surface shape and thickness is the best with this cleaning method. Taking this into account, and the previous conclusion (Figure 3), it has been assumed that cleaning in (b) way is the most optimal one.

\subsection{Dielectric layers}

Examples of surface dielectric layers profile printed on Melinex OD substrates are presented in Figure 7. Figure 7(a) and 7 (b) show; respectively, a homogeneous surface and a heterogeneous structure in which the discontinuities of the layer can be seen. Analyzing Figure 7, it can be noticed that the

Figure 5 (a) Surface profile of printed structure cleaning in (a) way; (b) surface profile of printed structure cleaning in (b) way; and (c) surface profile of printed structure cleaning in (c) way

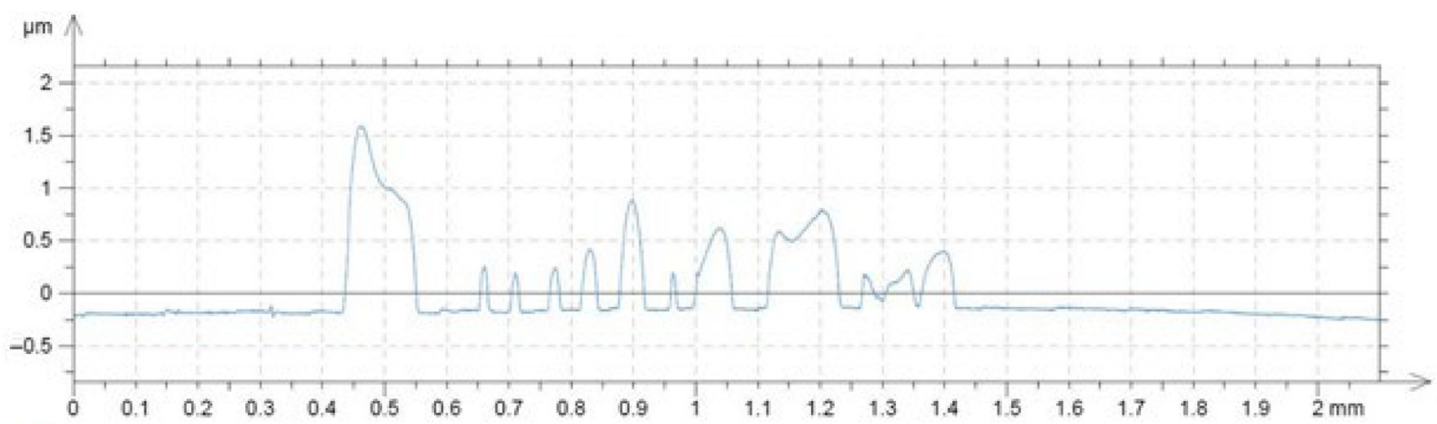

(a)

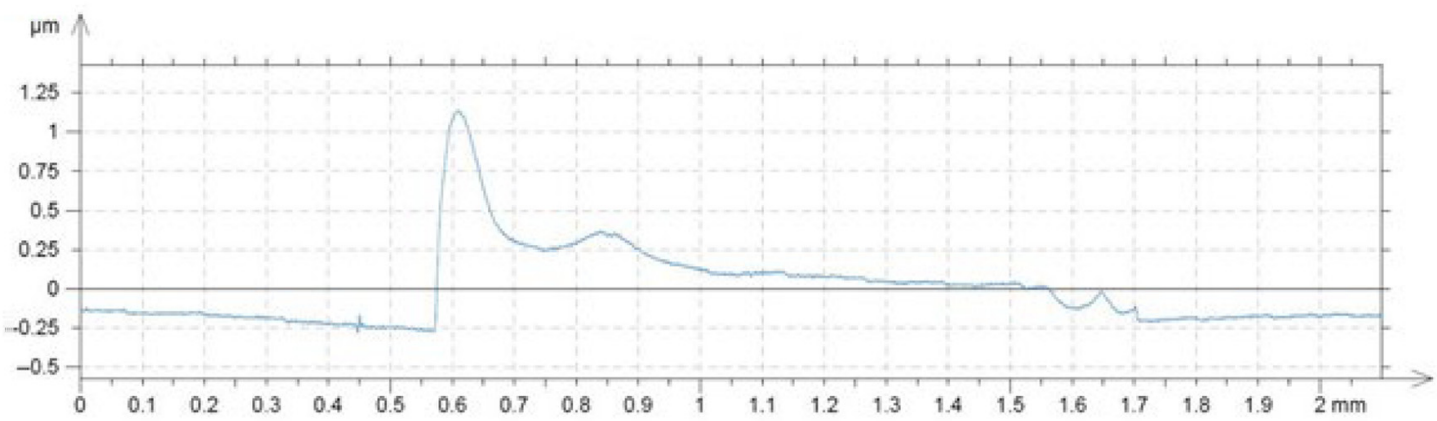

(b)

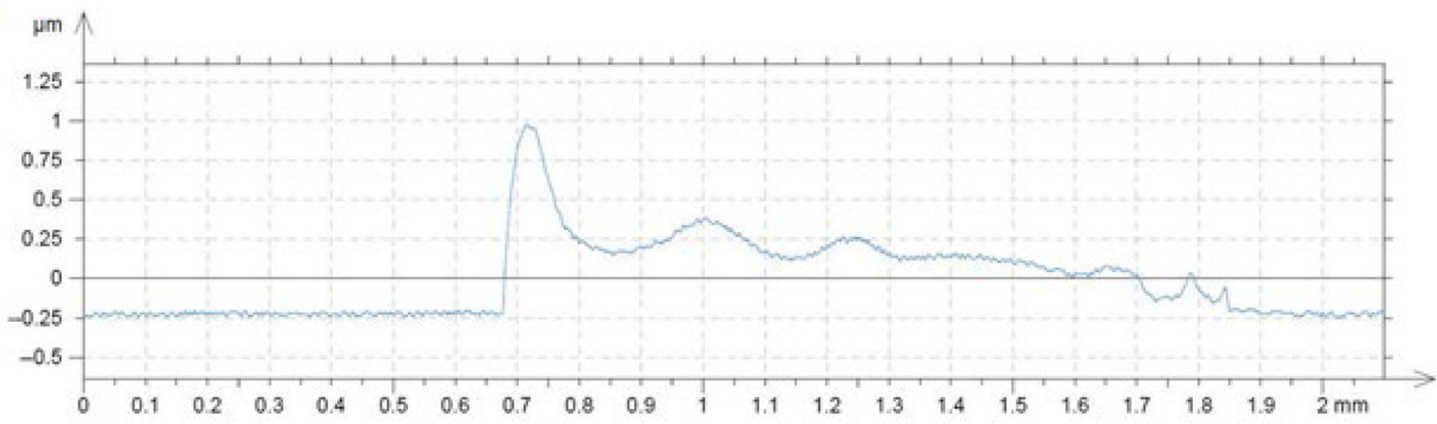

(c) 
homogeneous structure characterized by continuous and even coverage of the substrate by ink, while the heterogeneous is unevenly covered, the ink did not cover the whole given area.

The parameters used to make a homogenous sample are drop space: $5 \mu \mathrm{m}$; printer hotplate: $30^{\circ} \mathrm{C}$; time curing: $30 \mathrm{~min}$ and temperature curing: $130^{\circ} \mathrm{C}$. The parameters used to make a heterogeneous sample are: drop space: $15 \mu \mathrm{m}$; printer hotplate: $50^{\circ} \mathrm{C}$; time curing: $30 \mathrm{~min}$ and temperature curing: $110^{\circ} \mathrm{C}$. Analyzing Figure 7, it was noticed that the homogeneous structure (Figure 7a) is covered with ink exactly, while the heterogeneous [Figure 7(b)] structure is unevenly covered, the ink did not cover the whole given area.

Technological parameters given above indicate in which conditions it is possible to make a better layer, but they do not propose optimal conditions resulting from the combination of parameters. In addition, it is not known whether an important technological parameter has been omitted. For answers to these questions, the DoE as the fractional factional experiment,

Figure 6 Full roughness analysis of conductive layers

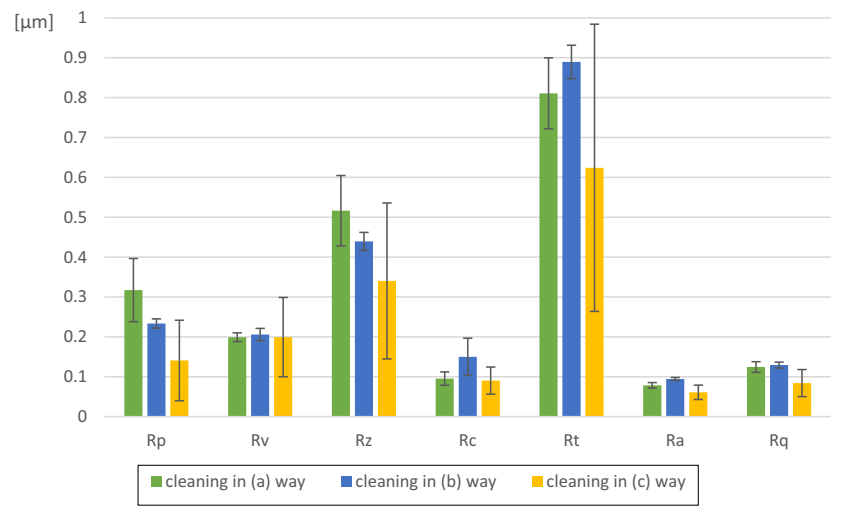

Notes: $\mathrm{R}_{\mathrm{p}}$ - maximum profile peak height; $\mathrm{R}_{\mathrm{v}}$ - maximum profile valley depth; $R_{z}$ - maximum height of profile; $R_{c}$ - mean height of profile elements; $R_{t}$ - total height of profile; $R_{a}$ - arithmetical mean height; $R_{q}-$ root mean square deviation

Figure 7 Surface profile: left - homogeneous and right - heterogeneous

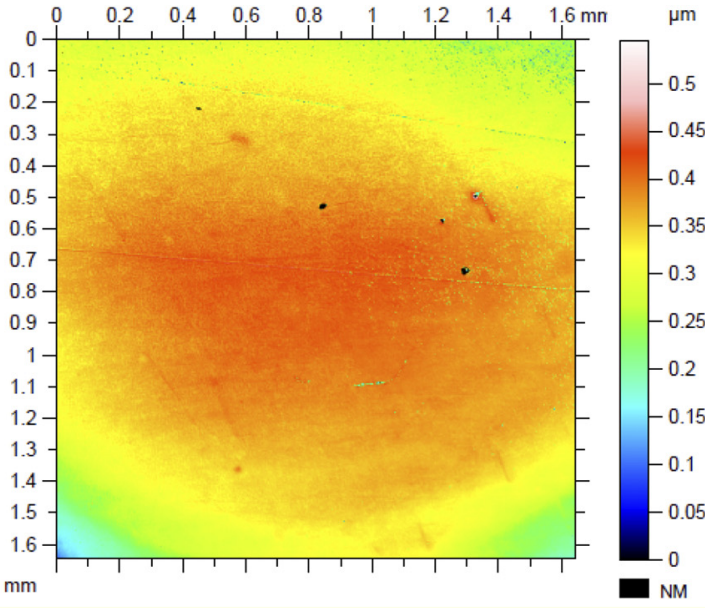

(a) according to Taguchi method (Ross, 1988), was proposed. Technological parameters were treated as experiment controllable factors which has two levels. The factors and levels were denoted as follows:

- A: drop space, (A1:5 $\mu \mathrm{m}$; A2: $15 \mu \mathrm{m})$;

- B: printer hotplate $\left(\mathrm{B} 1: 30^{\circ} \mathrm{C} ; \mathrm{B} 2: 50^{\circ} \mathrm{C}\right)$;

- C: time curing (C1:40 min; $\mathrm{C} 2: 30 \mathrm{~min})$; and

- D: temperature curing (D1: $\left.110^{\circ} \mathrm{C} ; \mathrm{D} 2: 130^{\circ} \mathrm{C}\right)$.

According to L8 orthogonal array, eight tests were performed, and each printed surface was analyzed three times in different areas. The results of the experiment were transformed by ANOVA. From ANOVA table (Table 1), it can be seen can see that only A factor with $99 \%$ and two factors with $95 \%$ confidence level (B and C) are important. Calculating main factorial effects and taking into account the criterion "the lower the better" $\mathrm{A} 1, \mathrm{~B} 1$ and $\mathrm{C} 2$, i.e. hotplate temperature: $30^{\circ} \mathrm{C}$, drop space: $5 \mu \mathrm{m}$ and time curing: $30 \mathrm{~min}$, were selected as more favorable. These values will be used in the next steps of searching optimal technological and material parameters. The factor of temperature curing is not important. Its participation is very little; therefore, it was not included in further studies. The error rate is $31.58 \%$, which is acceptable value for the

Table 1 ANOVA table

\begin{tabular}{lccccccc}
\hline Factor & SS & v & V & SS' $^{\prime}$ & P & $(\%)$ & F \\
\hline A & 9.76 & 1 & 9.76 & 9.46 & $4.22 \mathrm{E}-01$ & 42.21 & $31.74^{* * *}$ \\
B & 3.01 & 1 & 3.01 & 2.70 & $1.21 \mathrm{E}-01$ & 12.07 & $9.79^{* *}$ \\
C & 3.48 & 1 & 3.48 & 3.17 & $1.41 \mathrm{E}-01$ & 14.14 & $11.30^{* *}$ \\
e & 6.15 & 20 & 0.31 & 7.08 & $3.16 \mathrm{E}-01$ & 31.58 & - \\
Total & 22.40 & 23 & - & - & - & 100 & -
\end{tabular}

Notes: (SS is the sum of squares; $v$ is degrees of freedom; $V$ is variance; SS 1 is model sum of squares; $P$ contribution the factor; $\%$ is percentage contribution; $\mathrm{F}$ is Fisher-Snedecor test ( $\mathrm{F}$ test); ${ }^{* * *}$ is factors with $99 \%$ confidence level; ** is factors with $95 \%$ confidence level)

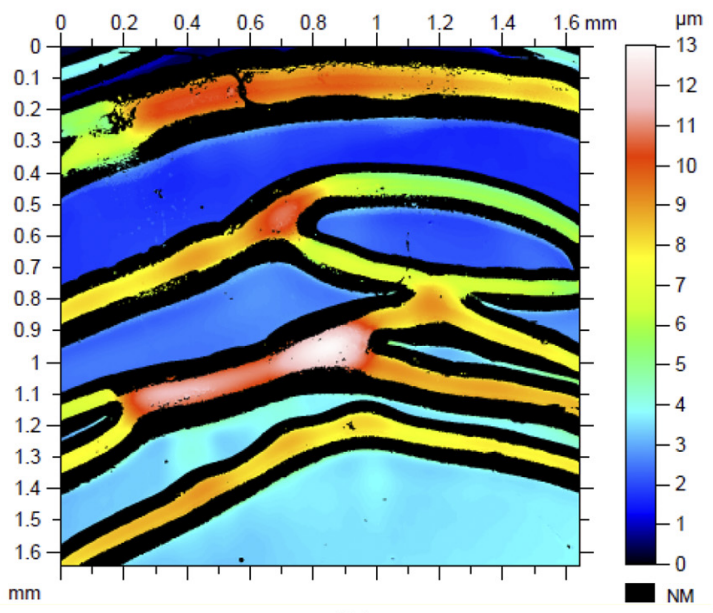

(b) 
experiment and indicates that factors with a high level of significance were not omitted in the experiment.

\subsection{Capacitors structure}

Further studies have shown that repetitive capacities of 0.4 $\mathrm{nF}$ occur when printing five layers and $0.25 \mathrm{nF}$ when printing ten layers (Surmiak, 2019) of cPVP.

\section{Conclusion}

The method of preparing the substrate affects the value of the base's wettability angle (Figure 2). The largest angle occurs when using only deionized water. The deviation of the printed structure is the least expensive for this cleaning method (Figure 3). However, there are discontinuities in the structure.

Using deionized water alone to clean the surface of the substrate does not remove all impurities owing to the poor solubility of organic compounds. It is therefore recommended to clean the substrates with additional cleaning agents. Studies have confirmed that the use of isopropanol to clean the surface improves the quality of the obtained prints.

Analysis of the printed structure using a mechanical profilometer showed high surface roughness and lack of homogeneity. It is, therefore, necessary to use a compromise between the accuracy and the consistency of the printed structure. The smaller deviation occurs in wider shapes.

The DoE method indicated the most important parameters when printing dielectric structures. For example, the temperature of the hotplate was observed on the roughness of the printed surface.

Despite the fact that the most important parameters are indicated on the value of dielectric surface roughness (and discontinuities), it is necessary to print several layers of dielectric. Research has revealed that capacitors printed with one or even two layers of cPVP are immeasurable. There is a short circuit between the silver capacitor wraps. This is unacceptable if the printed layers of the capacitor structures are repeatable.

Accurate analysis of dielectric layers enabled the printing of repeatable structures of capacitors. Capacitor structures are the basis for printing transistors.

\section{References}

Amepox (2020), "Nano ink AX JP-60n, low temperature conductive ink for jet printing", available at: www.amepoxmc.com/cache/files/1382424142_Nano-Ink_AX_JP-60n.pdf (accessed 29 March 2020).

Brodeala, A., Bonea, A., Alcade, A., Mihailescu, B., Vasile, A. and Svasta, P. (2012), "Electrical characterization of ink-jet printed organic capacitors on flexible substrate", Advanced Topics in Optoelectronics, Microelectronics, and Nanotechnologies VI, 8411(August), p. 84111B, doi: 10.1117/12.963740.

De Gans, B.J., Duineveld, P.C. and Schubert, U.S. (2004), "Inkjet printing of polymers: state of the art and future developments", Advanced Materials, Vol. 16 No. 3, pp. 203-213, doi: 10.1002/adma.200300385.
Felba, J. (2018), "Silver nanoparticles for inkjet-printed conductive structures in electronic packaging", in Morris. Portland J.E. (Ed.), Second, Nanopackaging: Nanotechnologies and Electronics Packaging, Second Edition. Second, Springer, doi: 10.1007/978-3-319-90362-0_4.

Jasińska, L., Szostak, K., Kiliszkiewicz, M., Słobodzian, P. and Malecha, K. (2019), "Ink-jet printed ring resonator with integrated microfluidic components", Circuit World, doi: 10.1108/CW-11-2019-0176 (November 2019).

Le, H.P. (1998), "Progress and trends in ink-jet printing technology", Fournal of Imaging Science and Technology, Vol. 42 No. 1, pp. 49-62.

Liu, Y., Cui, T. and Varahramyan, K. (2003), "All-polymer capacitor fabricated with inkjet printing technique", SolidState Electronics, Vol. 47 No. 9, pp. 1543-1548, doi: 10.1016/ S0038-1101(03)00082-0.

Miettinen, J., Pekkanen, V., Kaija, K., Mansikkamäki, P., Mäntysalo, J., Mäntysalo, M., Niittynen, J., Pekkanen, J., Saviauk, T. and Rönkkä, R. (2008), "Inkjet printed system-inpackage design and manufacturing", Microelectronics fournal, Vol. 39 No. 12, pp. 1740-1750, doi: 10.1016/j.mejo.2008.02.014.

Perelaer, J., Smith, P.J., Mager, D., Soltman, D., Volkman, S.K., Subramanian, V., Korvink, J.G. and Schubert, U.S. (2010), "Printed electronics: the challenges involved in printing devices, interconnects, and contacts based on inorganic materials", Fournal of Materials Chemistry, Vol. 20 No. 39, pp. 8446-8453, doi: 10.1039/c0jm00264j.

Ross, P.J. (1988), "Taguchi techniques for quality engineering",

Sowade, E., Göthel, F., Zichner, R. and Baumann, R.R. (2015), "Inkjet printing of UHF antennas on corrugated cardboards for packaging applications", Applied Surface Science, Vol. 332, pp. 500-506, doi: 10.1016/j. apsusc.2015.01.113.

Sowade, E., Ramon, E., Mitra, K.Y., Martínez-Domingo, C., Pedró, M., Pallarès, J., Loffredo, F., Villani, F., Gomes, H.L., Terés, L. and Baumann, R.R. (2016), “Allinkjet-printed thin-film transistors: manufacturing process reliability by root cause analysis", Scientific Reports, Vol. 6 No. 1, pp. 1-15, doi: 10.1038/srep33490.

Surmiak, A. (2019), "Ocena możliwości drukowania strumieniowego struktur wielowarstwowych o różnych właściwościach elektrycznych", Master Thesis, WUST, supervisior Jan Felba.

Szostak, K., Kiliszkiewicz, M., Jasińska, L., Słobodzian, P., Korbutowicz, R. and Malecha, K. (2019), "Inkjet printed vs screen printed microstrip line on LTCC substrates", Conference on Microwave Techniques, COMITE 2019 Microwave and Radio Electronics Week, MAREW 2019, doi: 10.1109/COMITE.2019.8733512.

Yuan, Y. and Lee, R.T. (2013), "Surface science techniques", Contact Angle and Wetting Properties, Berlin, Heidelberg, Springer. doi: 10.1007/978-3-642-34243-1.

\section{Corresponding author}

Milena Kiliszkiewicz can be contacted at: milena. kiliszkiewicz@pwr.edu.pl 